\title{
Setting the Stage for Self-Regulated Learning Instruction and Metacognition Instruction in Musical Practice
}

\author{
Hans-Christian Jabusch * \\ Institute of Musicians' Medicine, University of Music Carl Maria von Weber Dresden, Dresden, Germany
}

Keywords: self-regulation, self-regulated learning, metacognition, performance cues, music, practice, memory

\section{A commentary on:}

Recording thoughts while memorizing music: a case study

by Lisboa, T., Chaffin, R., and Demos, A. (2015). Front. Psychol. 5:1561. doi: 10.3389/fpsyg.2014.01561

Over the last two decades, the concept of self-regulated learning (SRL) has guided scientific approaches to understand successful learning in different fields. Self-regulatory processes were shown to explain achievement differences in students, and SRL may effectively improve achievement in students of different proficiency levels (Zimmerman and Schunk, 2011). Selfregulation refers to "self-generated thoughts, feelings, and actions that are planned and cyclically adapted to the attainment of personal goals" (Zimmerman, 2000, p. 14). Three interacting learning phases have been described: forethought (characterized by goal setting, strategic planning, selfbeliefs), performance phase (with the application of strategies, self-observation), and self-reflection (including self-evaluation, attribution, self-reaction). Self-regulated actions and processes include feedback-loops on the personal, behavioral, and environmental level (Zimmerman, 2000). In the educational literature, the terms SRL and metacognition are sometimes used interchangeably (Dinsmore et al., 2008). Although there is a common conceptual core, metacognition and selfregulation are different constructs with different roots. Metacognition was originally referred to as knowledge about and regulation of one's cognitive activities in learning processes (Veenman and van Hout-Wolters, 2006). Central components are metacognitive knowledge, i.e., one's knowledge or beliefs about the interactions between person, task, and strategy characteristics, and metacognitive skills, i.e., the knowledge required for the regulation of and control over one's learning activities (Brown, 1978; Flavell, 1979; Veenman and Spaans, 2005). Metacognition plays a crucial role in successful learning. A large review study based on a meta-analysis of 179 sources identified metacognition as having the strongest influence on school learning (followed by classroom management, quantity of instruction, and social student/teacher interaction) among 30 potential predictor variables (Wang et al., 1990). As a consequence, metacognitive processes are of great interest for pedagogy in various domains.

While there is a wide body of literature on SRL and metacognition in academic disciplines, a limited number of studies have been published on SRL and metacognition in musical practice. Based on findings in advanced music students, S.G. Nielsen proposed a cyclical model which identified the student's problem beliefs, strategy use, self-evaluation, and their interrelations as core elements of successful musical practice (Nielsen, 2001). In this model, the different steps and decisions in the practice process are modulated through metacognitive knowledge and regulation. 
In their seminal framework for studying SRL in music, McPherson and colleagues applied Zimmerman's principles and dimensions of self-regulation to musical practice and development (McPherson and Renwick, 2001, 2011; McPherson and Zimmerman, 2011; McPherson et al., 2012, 2013). In a longitudinal study, they demonstrated how musical skills developed in 157 children over a 3-year period depending on the degree of SRL, e.g., in the musical subskills sight-reading, playing from memory, and playing by ear (McPherson, 2005; McPherson et al., 2012).

Differences in engaging in self-regulatory processes appear very early in the musical training and account for a large part of a student's subsequent progress (McPherson and Renwick, 2011). The question arises whether specific instruction may facilitate the development of SRL and metacognitive skills especially in young musicians and in early stages of musical education. Implications of observational studies, surveys and case studies led to valuable recommendations for music pedagogy (e.g., McPherson and Zimmerman, 2011; McPherson et al., 2013). In a systematic review, self-regulatory behavior in musicians was strongly related to self-regulation instruction, however, the underlying numbers were small, especially in beginner level musicians (Varela et al., 2014). Intervention studies on SRL- and metacognition instruction are scarce.

In the project reported by Lisboa et al. (2015), the application of a metacognitive strategy was investigated in a young nonexpert musician memorizing a piano composition. The authors' scientific focus, the so-called performance cues (PCs) based on recorded thoughts during practice, were previously shown to facilitate memorizing in an expert musician (Chaffin and Imreh, 2002). This benefit was regarded as a result of the musician's increased metacognitive awareness of goals and strategies in memorizing-one crucial element of self-regulated practice (Lisboa et al., 2015). The role of PCs in memorizing music shall briefly be described. Memorizing music and recalling by memory, i.e., learning to play a piece without the score, is one of the challenges in Western music performance tradition (Aiello and Williamon, 2002). How do musicians manage to reliably memorize and recall the enormous amount of information provided by a music score? Two kinds of memory are involved. Serial chaining develops automatically during practice based on implicit, procedural learning and may result in very accurate motor sequences (Rubin, 2006; Chaffin, 2011). Memory lapses, however, may lead to a breakdown of the performance if no "safety net" is available. Less experienced musicians tend to rely on serial chaining, whereas expert musicians additionally establish a mental map of the musical work based on the analysis of the musical structure (Aiello and Williamon, 2002; Chaffin, 2011). Consistent with the skilled memory theory of Chase and Ericsson, expert musicians create a safety net by developing hierarchically ordered retrieval schemes (Chase and Ericsson, 1982; Ericsson and Kintsch, 1995; Aiello and Williamon, 2002; Williamon and Valentine, 2002). They use PCs as landmarks which guide them through the process of recalling and playing the piece (Chaffin and Imreh, 2002; Chaffin et al., 2010; Chaffin, 2011; Ginsborg and Chaffin, 2012; Ginsborg et al., 2012). PCs are established by repeatedly thinking about (a) structural, (b) expressive, (c) interpretative, and (d) basic technical aspects (Chaffin, 2011).

Lisboa et al. (2015) wondered whether music students could benefit from PCs-similarly to expert musicians-and invited an 18-years old piano student with no prior experience in intentionally memorizing music to participate in a single-case study. In order to support the student's efforts to memorize a short piano work the teacher asked her to record her playingrelated thoughts on copies of the music score. Concurrent or retrospective reports of thoughts are an established method to gain insight into cognitive and metacognitive processes in musical practice (Nielsen, 1997; McPherson et al., 2013). Specifically, the student was asked to document the features of the music she was paying particular attention to while she practiced and to indicate the respective locations in the score by arrows. The student was not informed about the idea of PCs. In the following lesson, the teacher classified the student's documented thoughts according to the abovementioned aspects (a)-(d). Over the $6 \frac{1}{2}$-weeks period of practice, a total of eight reports of the student's thoughts either during practice or while performing from memory were made. $9 \frac{1}{2}$ weeks after the end of the practice period the student reconstructed and played the piece again by memory without having played it in the meantime. Video recordings of practice, of performances and of the reconstruction session allowed the researchers to identify the locations at which the student started and stopped playing. The starting points were analyzed in combination with the locations and nature of thoughts during practice and performances. Results showed that (1) thoughts in performances occurred at locations at which thoughts had occurred during precedent practice sessions; (2) thoughts in performances occurred at locations where the student had started playing in precedent practice sessions; (3) locations of thoughts were relatively stable over time but the nature of thoughts at particular locations sometimes changed; (4) reconstructing and playing the piece $91 / 2$ weeks later, the student used thoughts from the performance at the end of the practice period as retrieval cues. Altogether, the findings supported the hypothesis that the student's thoughts were PCs.

Lisboa et al. (2015) identified the use of PCs as a metacognitive strategy in a non-expert musician. Although this is a singlecase study with no cross-over design, the findings provide important insights into the metacognition and self-regulation of memorizing music by showing that a musician with no history of intentionally memorizing music developed PCs by recording thoughts. The procedure required little specific instruction.

Recommendations on SRL- and metacognition instructions are mainly based on case studies, observational studies and surveys. With their efforts to provide effective practice strategies and address metacognition in the lesson, teachers often do not reach their students (Bathgate and Schunn, 2013; Miksza and Tan, 2015). Most musicians do not feel that their training has assisted them in developing metacognitive skills (Barry and Hallam, 2002). In school learning, effects of SRL instructions were larger when provided by researches instead of regular teachers (Dignath and Büttner, 2008). In a small number of controlled studies undertaken on musical practice, heterogeneous results were seen after short term interventions. 
Self-evaluation instruction had no significant impact on selfevaluation accuracy or performance in music students after a 5weeks intervention (Hewitt, 2011). Two weeks of metacognitive instructions by teachers specifically trained in metacognitive teaching resulted in higher performance ratings in music students after 2 weeks of practice when compared with students after control instruction and practicing regularly (Bathgate et al., 2012). Similarly, a positive effect was seen after video-based selfregulation instruction in undergraduate music majors after 5 days of practice (Miksza, 2015). In a non-controlled study, 25 music students developed stronger self-regulatory skills after using a digital tool designed specifically to enhance self-regulation for 12 months (Upitis et al., 2012).

The study by Lisboa et al. (2015) and previous research have opened the door to a fascinating and promising area in music education research. We have the opportunity to continue this line of research and systematically address the questions resulting from their findings, with a special focus on controlled intervention studies and on early stages of musical education. These questions may include: (a) Can the findings of the singlecase study by Lisboa et al. (2015) be replicated in a larger series of young musicians and in a controlled study design? (b) Which types and which elements of instruction may support the development of metacognitive skills and SRL in young musicians? (c) To which extent is metacognition and SRL specific (e.g., instrument-, performer-, age-specific; specific to a level of expertise) or general? (d) Does the nature of SRL- and metacognition instruction effective in the individual depend on the variables mentioned in (c) or on personality traits? (e) Are metacognitive skills and SRL acquired in other domains helpful in the musical domain and vice versa? (f) Does (early) instruction of metacognitive skills and SRL in the musical domain have an influence on performance quality in the long-term view or

\section{REFERENCES}

Aiello, R., and Williamon, A. (2002). "Memory," in The Science and Psychology of Music Performance: Creative Strategies for Teaching and Learning, eds R. Parncutt and G. E. McPherson (Oxford: Oxford University Press), 167-181.

Barry, N., and Hallam, S. (2002). "Practice," in The Science and Psychology of Music Performance: Creative Strategies for Teaching and Learning, eds R. Parncutt and G. E. McPherson (Oxford: Oxford University Press), 151-165.

Bathgate, M. E., Sims-Knight, J. E., and Schunn, C. D. (2012). Thoughts on thinking: engaging novice music students in metacognition. Appl. Cognit. Psychol. 26, 403-409. doi: 10.1002/acp.1842

Bathgate, M., and Schunn, C. D. (2013). "Exploring and encouraging metacognitive awareness in novice music students," in Developing the Musician: Contemporary Perspectives on Teaching and Learning, ed M. Stakelum (London; New York: Routledge), 247-264.

Brown, A. L. (1978). "Knowing when, where, and how to remember: a problem of metacognition," in Advances in Instructional Psychology, Vol. 1, ed R. Glaser (Hillsdale, NJ: Lawrence Erlbaum Associates), 77-165.

Chaffin, R. (2011). "Thinking about performance: memory, attention, and practice," in Proceedings of the International Symposium on Performance Science 2011, eds A. Williamon, D. Edwards, and L. Bartel (Utrecht: European Association of Conservatoires (AEC)), 689-699.

Chaffin, R., and Imreh, G. (2002). Practicing perfection: piano performance as expert memory. Psychol. Sci. 13, 342-349. doi: 10.1111/j.0956-7976.2002.00462.x on emotional issues such as performance anxiety or musicians' emotional attachment to their instrument? To further improve our knowledge on the instruction of metacognition and SRL in musical practice will be of great interest to cognitive psychologists and to musicians and music teachers.

\section{AUTHOR CONTRIBUTIONS}

The author confirms being the sole contributor of this work and approved it for publication.

\section{FUNDING}

$\mathrm{HJ}$ is head of the Institute of Musicians' Medicine (IMM) at the University of Music Carl Maria von Weber, Dresden, Germany, and is a full professor paid by the University of Music Carl Maria von Weber. He has received funding from the Dystonia Coalition (NS065701; The Dystonia Coalition is part of the NIH Rare Diseases Clinical Research Network and has support from the NIH Office of Rare Diseases Research and National Institute of Neurological Disorders and Stroke). He has received speaker honoraria from the Berlin University of the Arts, Germany (2014, 2015), from the Hof Symphony Orchestra and the Association of Musicians High Franconia, Germany (2015), from the International Summer Academy Lüneburger Heide, Germany (2015), from the Saxony State Music Council, Germany (2015), from the Klinik Bosse Wittenberg Alexianergemeinschaft GmbH (2015), and from the University of Music and Performing Arts Vienna (2015). The IMM has received free pharmaceutical samples from IPSEN PHARMA GmbH. The IMM has received funding from a private donor without ties to the psychological field.

Chaffin, R., Lisboa, T., Logan, T., and Begosh, K. T. (2010). Preparing for memorized cello performance: the role of performance cues. Psychol. Music 38, 3-30. doi: 10.1177/0305735608100377

Chase, W. G., and Ericsson, K. A. (1982). "Skill and working memory", in The Psychology of Learning and Motivation, vol. 16, ed G. H. Bower (New York, NY: Academic Press), 1-58.

Dignath, C., and Büttner, G. (2008). Components of fostering self-regulated learning among students: a meta-analysis on intervention studies at primary and secondary school level. Metacogn. Learn. 3, 231-264. doi: 10.1007/s11409008-9029-x

Dinsmore, D. L., Alexander, P. A., and Loughlin, S. M. (2008). Focusing the conceptual lens on metacognition, self-regulation, and self-regulated learning. Educ. Psychol. Rev. 20, 391-409. doi: 10.1007/s10648-0089083-6

Ericsson, K. A., and Kintsch, W. (1995). Long-term working memory. Psychol. Rev. 102, 211-245. doi: 10.1037/0033-295X.102.2.211

Flavell, J. H. (1979). Metacognition and cognitive monitoring. A new area of cognitive-developmental inquiry. Am. Psychol. 34, 906-911. doi: 10.1037/0003066X.34.10.906

Ginsborg, J., and Chaffin, R. (2012). Preparation and spontaneity in performance: a singer's thoughts while singing Schoenberg. Psychomusicology 21, 137-158. doi: 10.1037/h0094009

Ginsborg, J., Chaffin, R., and Demos, A. P. (2012). Different roles for prepared and spontaneous thoughts: a practice-based study of musical performance from memory. J. Interdiscip. Music Stud. 6, 201-231. doi: 10.4407/jims.2014.02.005 
Hewitt, M. P. (2011). The impact of self-evaluation instruction on student selfevaluation, music performance, and self-evaluation accuracy. J. Res. Music Educ. 59, 6-20. doi: 10.1177/0022429410391541

Lisboa, T., Chaffin, R., and Demos, A. (2015). Recording thoughts while memorizing music: a case study. Front. Psychol. 5:1561. doi: 10.3389/fpsyg.2014.01561

McPherson, G. E. (2005). From child to musician: skill development during the beginning stages of learning an instrument. Psychol. Music 33, 5-35. doi: 10.1177/0305735605048012

McPherson, G. E., Davidson, J. W., and Faulkner, R. (2012). Music in Our Lives: Rethinking Musical Ability, Development and Identity. Oxford: Oxford University Press.

McPherson, G. E., Nielsen, S. G., and Renwick, J. M. (2013). "Self-regulation interventions and development of music expertise," in Applications of SelfRegulated Learning Across Diverse Disciplines, eds H. Bembenutty, T. J. Cleary, and A. Kitsantas (Charlotte, NC: Information Age Publishing), 355-382.

McPherson, G. E., and Renwick, J. M. (2001). A longitudinal study of selfregulation in children's musical practice. Music. Educ. Res. 3, 169-186. doi: 10.1080/14613800120089232

McPherson, G. E., and Renwick, J. M. (2011). "Self-regulation and mastery of musical skills," in Handbook of Self-Regulation of Learning and Performance, eds B. J. Zimmerman and D. H. Schunk (New York, NY: Routledge), 234-248.

McPherson, G. E., and Zimmerman, B. J. (2011). "Self-regulation of musical learning: a social cognitive perspective on developing performance skills," in MENC Handbook of Research on Music Learning, vol. 2: Applications, eds R. Colwell and P. Webster (New York, NY: Oxford University Press), 130-175. doi: 10.1093/acprof:osobl/9780199754397.003.0004

Miksza, P. (2015). The effect of self-regulation instruction on the performance achievement, musical self-efficacy, and practicing of advanced wind players. Psychol. Music 43, 219-243. doi: 10.1177/0305735613500832

Miksza, P., and Tan, L. (2015). Predicting collegiate wind players' practice efficiency, flow, and self-efficacy for self-regulation: an exploratory study of relationships between teachers' instruction and students' practicing. J. Res. Music Educ. 63, 162-179. doi: 10.1177/0022429415583474

Nielsen, S. (2001). Self-regulating learning strategies in instrumental music practice. Music. Educ. Res. 3, 155-167. doi: 10.1080/14613800120089223

Nielsen, S. G. (1997). "Verbal protocol analysis and research on instrumental music practice," in Third Triennial ESCOM Conference, Proceedings, ed A. Gabrielsson (Uppsala: UppsalaUniversity), 183-188.
Rubin, D. C. (2006). The basic-system model of episodic memory. Perspect. Psychol. Sci. 1, 277-311. doi: 10.1111/j.1745-6916.2006.00017.x

Upitis, R., Brook, J., Abrami, P. C., Varela, W., and Elster, A. (2012). "Revitalizing studio music learning through digital portfolios," in Proceedings of the Twentyfourth International Seminar on Research in Music Education (Thessaloniki: University of Macedonia), 239-246.

Varela, W., Abrami, P. C., and Upitis, R. (2014). Self-regulation and music learning: a systematic review. Psychol. Music 44, 55-74. doi: 10.1177/03057356145 54639

Veenman, M. V. J., and Spaans, M. A. (2005). Relation between intellectual and metacognitive skills: age and task differences. Learn. Individ. Differ. 15, 159-176. doi: 10.1016/j.lindif.2004.12.001

Veenman, M. V. J., and van Hout-Wolters, B. H. A. M. (2006). Metacognition and learning: conceptual and methodological considerations. Metacogn. Learn. 1, 3-14. doi: 10.1007/s11409-006-6893-0

Wang, M. C., Haertel, G. D., and Walberg, H. J. (1990). What influences learning? A content analysis of review literature. J. Educ. Res. 84, 30-43. doi: 10.1080/00220671.1990.10885988

Williamon, A., and Valentine, E. (2002). The role of retrieval structures in memorizing music. Cognit. Psychol. 44, 1-32. doi: 10.1006/cogp.20 01.0759

Zimmerman, B. J. (2000). “Attaining self-regulation: a social cognitive perspective,” in Handbook of Self-Regulation, eds M. Boekaerts, P. R. Pintrich, and M. Zeidner (San Diego, CA: Academic Press), 13-39. doi: 10.1016/b978-0121098902/50031-7

Zimmerman, B. J., and Schunk, D. H. (2011). "Self-regulated learning and performance: an introduction and an overview," in Handbook of Self-Regulation of Learning and Performance, eds B. J. Zimmerman and D. H. Schunk (New York, NY: Routledge), 1-12.

Conflict of Interest Statement: The author declares that the research was conducted in the absence of any commercial or financial relationships that could be construed as a potential conflict of interest.

Copyright (c) 2016 Jabusch. This is an open-access article distributed under the terms of the Creative Commons Attribution License (CC BY). The use, distribution or reproduction in other forums is permitted, provided the original author (s) or licensor are credited and that the original publication in this journal is cited, in accordance with accepted academic practice. No use, distribution or reproduction is permitted which does not comply with these terms. 